\title{
Optimization and analysis of novel thermoelectric module
}

\author{
Pradyumn Mane ${ }^{1}$, Deepali Atheaya ${ }^{2}$ \\ ${ }^{1}$ Engineering Physics Department, School of Engineering and Applied Sciences, Bennett University, \\ Tech Zone - II, Greater Noida, 201310, UP, India \\ ${ }^{2}$ Mechanical and Aerospace Engineering Department, School of Engineering and Applied Sciences, \\ Bennett University, Tech Zone - II, Greater Noida, 201310, UP, India \\ ${ }^{1}$ Corresponding author \\ E-mail: ${ }^{1}$ pradyumnmane@gmail.com, ${ }^{2}$ deepali.atheaya@bennett.edu.in
}

Received 24 September 2019; accepted 1 October 2019

DOI https://doi.org/10.21595/vp.2019.21057

Check for updates

Copyright $(2019$ Pradyumn Mane, et al. This is an open access article distributed under the Creative Commons Attribution License, which permits unrestricted use, distribution, and reproduction in any medium, provided the original work is properly cited.

\begin{abstract}
Optimization and analysis of novel thermoelectric module is proposed in this research paper. The simulation for four thermoelectric modules were performed in COMSOL Multiphysics 5.4 software and detailed analysis of these thermoelectric modules were carried out. The three thermoelectric modules showed the efficiency and power output above-average thermoelectric modules. It also indicated that lead telluride based thermoelectric modules could be used in isolated areas due to toxicity of lead whereas tetrahedrite based thermoelectric module could be used in non-isolated areas due to its non-toxic properties. The proposed thermoelectric modules can be utilized in applications such as industries, deep space explorations, automobiles, thermal power plants, renewable electricity generation, hybrid renewable systems, etc. in an economically viable manner.
\end{abstract}

Keywords: thermoelectric module, lead telluride, tetrahedrites, skutterudites, perovskites.

\section{Nomenclature}

V

$R_{p}$

$R_{n}$

$R$

I

$P$

$T_{C}$

$T_{H}$

$T$

$S$

$S_{p}$

$S_{n}$

$\rho_{p}$

$\rho_{n}$

$\sigma_{p}$

$\sigma_{p}$

$k_{p}$

$k_{n}$

$z T$

$Z T$

$\eta$
Thermoelectric voltage output

Net resistance of $p$-type thermoelectric legs

Net resistance of $n$-type thermoelectric legs

Net resistance of thermoelectric module

Thermoelectric current

Thermoelectric power output

Temperature at the cold terminal

Temperature at the hot terminal

Temperature difference

Seebeck coefficient

Seebeck coefficient of the $p$-type thermoelectric leg

Seebeck coefficient of the $n$-type thermoelectric leg

Resistivity of the $p$-type thermoelectric leg

Resistivity of the $n$-type thermoelectric leg

Electrical conductivity of $p$-type thermoelectric leg

Electrical conductivity of $n$-type thermoelectric leg

Thermal conductivity of $p$-type thermoelectric leg

Thermal conductivity of $n$-type thermoelectric leg

Figure of merit of a thermoelectric leg/thermoelectric material

Figure of merit of the thermoelectric module

Thermoelectric performance efficiency 


\section{Introduction}

Thermoelectricity works on Seebeck principle which states, "The Seebeck effect is a phenomenon in which the temperature difference between two dissimilar electrical conductors or semiconductors produces voltage difference between the two substances". The work to increase performance efficiency $(\eta)$ of thermoelectric modules is going since decades and so far 5-8\% efficiency $(\eta)$ could be achieved [1]. In 2009, Alphabet Energy invested $\$ 49.5$ million to develop waste heat recovery thermoelectric generator and claimed to have an efficiency $(\eta)$ of $5 \%$ and ensured to go above $10 \%$ in upcoming years. A group of researchers from Swiss Federal Laboratories for Materials Testing and Research, High Voltage Laboratories and Institute of Physics of ASCR experimented $\mathrm{GdCo}_{0.95} \mathrm{Ni}_{0.05} \mathrm{O}_{3}$ and $\mathrm{CaMn}_{0.98} \mathrm{Nb}_{0.02} \mathrm{O}_{3}$ thermoelectric materials and thermoelectric modules and evaluated their power characteristics [2]. Fu et al. [3] designed quaternary alloys of $\mathrm{Pb}_{1-\mathrm{x}} \mathrm{Mg}_{\mathrm{x}} \mathrm{Te}_{0.8} \mathrm{Se}_{0.2}$ and achieved a figure of merit $(z T)$ of 2.2 at $820 \mathrm{~K}$. Chen [1] from Queen Mary University of London provided a comprehensive study on synthesis method, crustal structures and thermoelectric properties of tetrahedrite compounds. Scientists from Panasonic experimented and studied the thermoelectric properties of skutterudites and achieved a figure of merit $(z T)$ of 1.1 at $820 \mathrm{~K}$ for the composition $\mathrm{CoSb}_{2.875} \mathrm{Te}_{0.125}$ [4]. Recently, Lan et al. [5] predicted fuel economy potential for a skutterudite thermoelectric generator and observed that $25 \%-50 \%$ of fuel efficiency is obtained in light-duty vehicles.

The simulation of various combinations of thermoelectric couples were performed and it was noted that $\mathrm{Pb}_{1-\mathrm{x}} \mathrm{Mg}_{\mathrm{x}} \mathrm{Te}_{0.8} \mathrm{Se}_{0.2}$ and $n$-type $\mathrm{PbTe}, \mathrm{Pb}_{1-\mathrm{x}} \mathrm{Mg}_{\mathrm{x}} \mathrm{Te}_{0.8} \mathrm{Se}_{0.2}$ and $\mathrm{CoSb}_{3-\mathrm{x}} \mathrm{Te}_{\mathrm{x}}$, $\mathrm{Pb}_{1-\mathrm{x}} \mathrm{Mg}_{\mathrm{x}} \mathrm{Te}_{0.8} \mathrm{Se}_{0.2}$ and $\mathrm{CaMn}_{0.98} \mathrm{Nb}_{0.02} \mathrm{O}_{3}, \mathrm{Cu}_{12} \mathrm{Sb}_{4} \mathrm{~S}_{13}$ and $\mathrm{CoSb}_{3-\mathrm{x}} \mathrm{Te}_{\mathrm{x}}$ indicated higher efficiency $(\eta)$ than other thermoelectric couples [6]. In this research paper, performance analysis of these optimized novel thermoelectric modules was carried out.

\section{Analysis of thermoelectric module}

Table 1 shows the simulated thermoelectric modules and their calculated and validated properties. From the table it can be concluded, that $\mathrm{Pb}_{1-\mathrm{x}} \mathrm{Mg}_{\mathrm{x}} \mathrm{Te}_{0.8} \mathrm{Se}_{0.2}$ and $n$-type $\mathrm{PbTe}$, $\mathrm{Pb}_{1-\mathrm{x}} \mathrm{Mg}_{\mathrm{x}} \mathrm{Te}_{0.8} \mathrm{Se}_{0.2}$ and $\mathrm{CoSb}_{3-\mathrm{x}} \mathrm{Te}_{\mathrm{x}}, \mathrm{Cu}_{12} \mathrm{Sb}_{4} \mathrm{~S}_{13}$ and $\mathrm{CoSb}_{3-\mathrm{x}} \mathrm{Te}_{\mathrm{x}}$ shows efficiency $(\eta)$ as predicted by Mane and Atheaya [6]. The detailed analysis of $\mathrm{Pb}_{1-\mathrm{x}} \mathrm{Mg}_{\mathrm{x}} \mathrm{Te}_{0.8} \mathrm{Se}_{0.2}$ and $\mathrm{CaMn}_{0.98} \mathrm{Nb}_{0.02} \mathrm{O}_{3}$ showed efficiency $(\eta)$ below $5 \%$. Therefore $\mathrm{Pb}_{1-\mathrm{x}} \mathrm{Mg}_{\mathrm{x}} \mathrm{Te}_{0.8} \mathrm{Se}_{0.2}$ and $\mathrm{CaMn}_{0.98} \mathrm{Nb}_{0.02} \mathrm{O}_{3}$ cannot be used to develop an efficient thermoelectric module.

Table 1. Thermoelectric modules and their properties

\begin{tabular}{|c|c|c|c|c|c|c|}
\hline \multicolumn{2}{|c|}{ Thermoelectric materials } & \multirow{2}{*}{ ZT } & \multirow{2}{*}{$\begin{array}{c}\eta \\
(\%)\end{array}$} & \multirow{2}{*}{$\begin{array}{l}\text { Power output } \\
\text { (W) }\end{array}$} & \multirow{2}{*}{$\begin{array}{c}\text { Voltage } \\
\text { (V) }\end{array}$} & \multirow{2}{*}{$\begin{array}{l}\text { Current } \\
\text { (A) }\end{array}$} \\
\hline P-type material & N-type material & & & & & \\
\hline $\mathrm{Pb}_{1-\mathrm{x}} \mathrm{Mg}_{\mathrm{x}} \mathrm{Te}_{0.8} \mathrm{Se}_{0.2}$ & $n$-type $\mathrm{PbTe}$ & 1.30 & 17 & 54.92 & 3.63 & 15.13 \\
\hline $\mathrm{Pb}_{1-\mathrm{x}} \mathrm{Mg}_{\mathrm{x}} \mathrm{Te}_{0.8} \mathrm{Se}_{0.2}$ & $\mathrm{CoSb}_{3-\mathrm{x}} \mathrm{Te}_{\mathrm{x}}$ & 1.20 & 16 & 60.96 & 3.20 & 19.05 \\
\hline $\mathrm{Cu}_{12} \mathrm{Sb}_{4} \mathrm{~S}_{13}$ & $\mathrm{CoSb}_{3-\mathrm{x}} \mathrm{Te}_{\mathrm{x}}$ & 0.6 & 10 & 14.57 & 2.77 & 5.26 \\
\hline $\mathrm{Pb}_{1-\mathrm{x}} \mathrm{Mg}_{\mathrm{x}} \mathrm{Te}_{0.8 \mathrm{Se}} \mathrm{Se}_{0.2}$ & $\mathrm{CaMn}_{0.98} \mathrm{Nb}_{0.02} \mathrm{O}_{3}$ & 0.11 & 2.4 & 6.31 & 3.41 & 1.85 \\
\hline
\end{tabular}

The unitless figure of merit (ZT) of thermoelectric module is the key entity to measure thermoelectric efficiency $(\eta)$ and is formulated as follows [1]:

$Z T=\frac{\left(S_{p}-S_{n}\right)^{2} T}{\left(\sqrt{\rho_{n} k_{n}}+\sqrt{\rho_{p} k_{p}}\right)^{2}}$.

The thermoelectric performance efficiency $(\eta)$ is mainly dependent on the figure of merit $(Z T)$ and is formulated as follows [1]: 
$\eta=\frac{T_{H}-T_{C}}{T_{H}} \frac{\sqrt{(1+Z T)}-1}{\sqrt{(1+Z T)}+\frac{T_{C}}{T_{H}}}$.

Thermoelectric voltage $(V)$ is induced when a temperature gradient is created and is formulated as follows [1]:

$V=\left(S_{p}-S_{n}\right) T$

Thermoelectric current $(I)$ was calculated by using Ohms law. The net resistance $(R)$ of the thermoelectric module was calculated by summing the resistance of thermoelectric legs:

$R_{p}=12 \rho_{p} \frac{l}{A}, \quad R_{n}=12 \rho_{n} \frac{l}{A}, \quad R=R_{p}+R_{n}, \quad I=\frac{V}{R}$

Thermoelectric power output $(P)$ is simply the product of thermoelectric voltage $(V)$ and the thermoelectric current $(I)$ :

$P=V I$.

\section{Results and discussion}

All thermoelectric modules were simulated and detailed investigation was carried out in COMSOL Multiphysics 5.4 software. The properties of thermoelectric materials were also validated in the simulation. The highest efficiency was found to be $17 \%$ and the results of this thermoelectric module have been discussed further.

The thermoelectric module was designed in COMSOL Multiphysics. The boundary conditions set to the module were $800 \mathrm{~K}$ and $300 \mathrm{~K}$ at the upper and lower surface respectively. Tetrahedral elements meshing was set manually for thermoelectric legs as well as copper metallic plates. Extremely fine mesh with minimum element size $8.6 \times 10^{-6}$ meters and maximum element size $5.6 \times 10^{-4}$ meters were set for thermoelectric legs to provide accurate results. Extra fine mesh with minimum element size $6.4 \times 10^{-5}$ meters and maximum element size $1.5 \times 10^{-3}$ meters were set for copper plates to reduce the computational time. High level element quality optimization was set to perform efficient meshing.

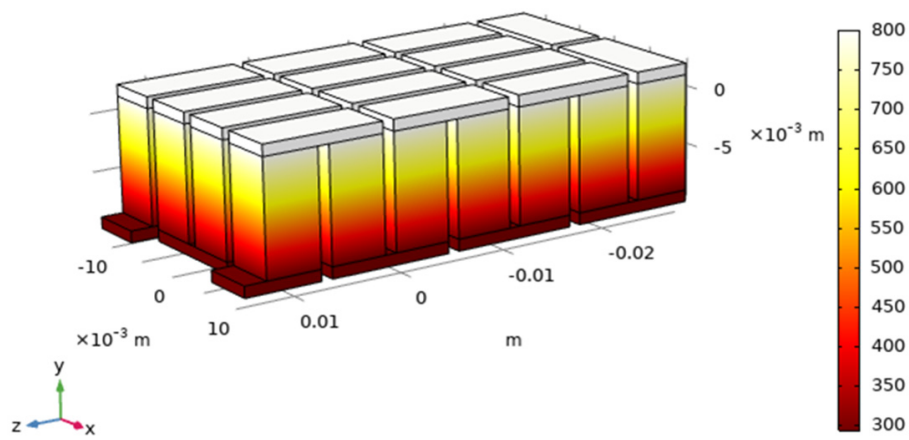

Fig. 1. Temperature distribution along the surface of the thermoelectric module

Fig. 1 displays the temperature distribution along the surface of the thermoelectric module. The module has a dimension of $43 \mathrm{~mm} \times 23 \mathrm{~mm} \times 12 \mathrm{~mm}$ and it comprises of twenty-four thermoelectric legs which were attached to copper metallic plates. The temperature at the hot terminal was set at $800 \mathrm{~K}$ and the temperature at the cold terminal was set at $300 \mathrm{~K}$. Fig. 1 displays that the temperature is evenly distributed along the surface of the thermoelectric module. 


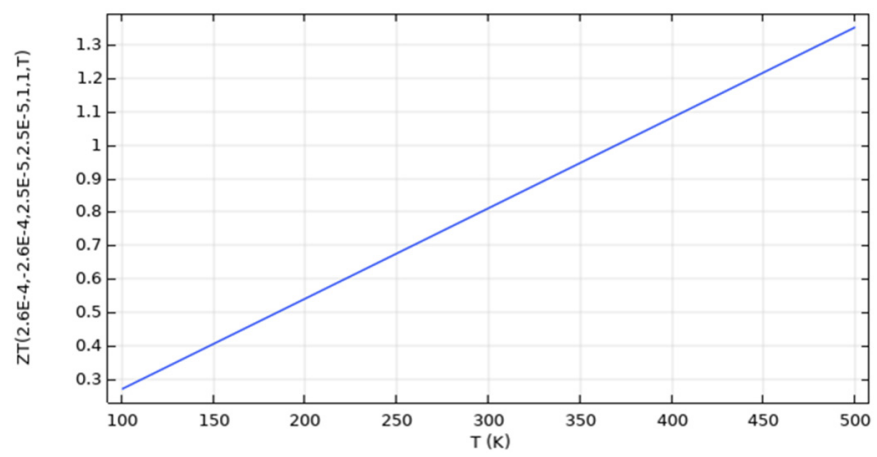

Fig. 2. Figure of merit $(Z T)$ with respect to temperature difference $(T)$ for $\mathrm{Pb}_{1-\mathrm{x}} \mathrm{Mg}_{\mathrm{x}} \mathrm{Te}_{0.8} \mathrm{Se}_{0.2}$ and $n$-type $\mathrm{PbTe}$ thermoelectric module

Fig. 2 demonstrates the figure of merit (ZT) for $\mathrm{Pb}_{1-\mathrm{x}} \mathrm{Mg}_{\mathrm{x}} \mathrm{Te}_{0.8} \mathrm{Se}_{0.2}$ and $n$-type $\mathrm{PbTe}$ thermoelectric module for various temperature difference $(T)$. At temperature difference of $100 \mathrm{~K}$ it was observed that figure of merit $(Z T)$ of approximately 0.3 was achieved whereas, at a temperature difference of $500 \mathrm{~K}$, the figure of merit $(Z T)$ of approximately 1.3 was achieved.

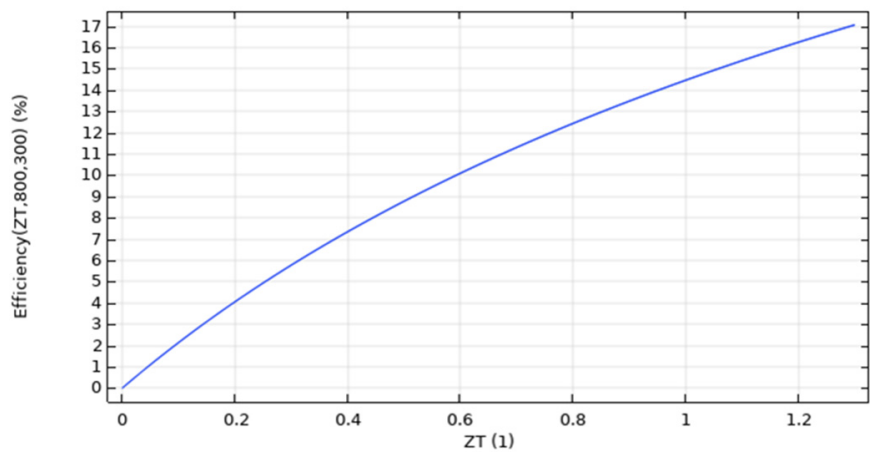

Fig. 3. Efficiency $(\eta)$ with respect to figure of merit $(Z T)$ for $\mathrm{Pb}_{1-\mathrm{x}} \mathrm{Mg}_{\mathrm{x}} \mathrm{Te}_{0.8} \mathrm{Se}_{0.2}$ and $n$-type $\mathrm{PbTe}$ thermoelectric module

The efficiency $(\eta)$ for $\mathrm{Pb}_{1-\mathrm{x}} \mathrm{Mg}_{\mathrm{x}} \mathrm{Te}_{0.8} \mathrm{Se}_{0.2}$ and $n$-type $\mathrm{PbTe}$ thermoelectric module has been presented in Fig. 3. It was observed that for figure of merit $(Z T)$ of 1.3 , an efficiency $(\eta)$ of $17 \%$ was achieved. Consequently, $\mathrm{Pb}_{1-\mathrm{x}} \mathrm{Mg}_{\mathrm{x}} \mathrm{Te}_{0.8} \mathrm{Se}_{0.2}$ and $n$-type $\mathrm{PbTe}$ thermoelectric module had the highest thermoelectric performance efficiency $(\eta)$ and it may be utilized to fabricate an efficient thermoelectric generator.

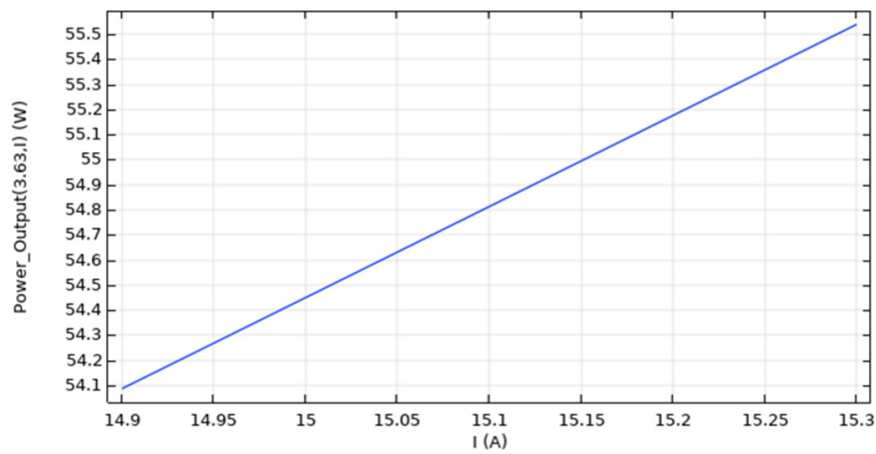

Fig. 4. Thermoelectric power output $(P)$ with respect to thermoelectric current $(I)$ for $\mathrm{Pb}_{1-\mathrm{x}} \mathrm{Mg}_{\mathrm{x}} \mathrm{Te}_{0.8} \mathrm{Se}_{0.2}$ and $n$-type $\mathrm{PbTe}$ thermoelectric module 
Fig. 4 displays the thermoelectric power output $(P)$ with respect to thermoelectric current $(I)$ for $\mathrm{Pb}_{1-\mathrm{x}} \mathrm{Mg}_{\mathrm{x}} \mathrm{Te}_{0.8} \mathrm{Se}_{0.2}$ and $n$-type $\mathrm{PbTe}$ thermoelectric module. It was observed that for thermoelectric current $(I)$ of $15.13 \mathrm{~A}$, power output $(P)$ of $54.92 \mathrm{~W}$ was achieved. Further, the current can be increased by increasing the area-length ratio of the thermoelectric module or by decreasing resistivity of the thermoelectric module.

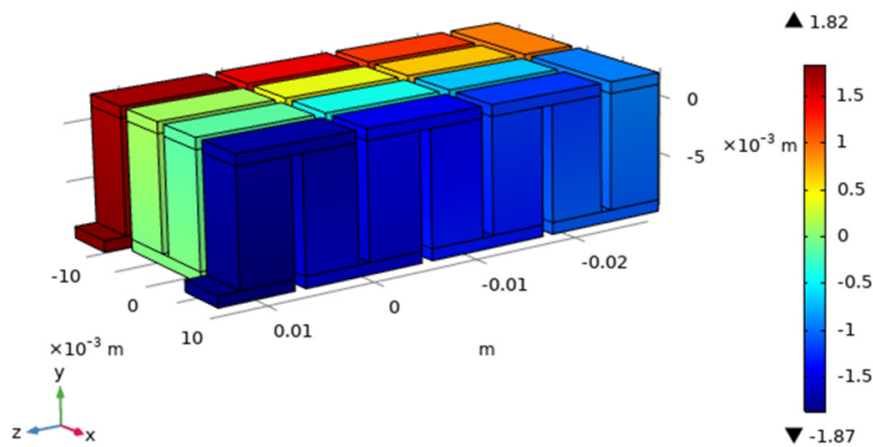

Fig. 5. Thermoelectric voltage output $(V)$ for $\mathrm{Pb}_{1-\mathrm{x}} \mathrm{Mg}_{\mathrm{x}} \mathrm{Te} \mathrm{e}_{0.8} \mathrm{Se}_{0.2}$ and $n$-type $\mathrm{PbTe}$ thermoelectric module

Fig. 5 displays the thermoelectric voltage output $(V)$ for $\mathrm{Pb}_{1-\mathrm{x}} \mathrm{Mg}_{\mathrm{x}} \mathrm{Te}_{0.8} \mathrm{Se}_{0.2}$ and $n$-type $\mathrm{PbTe}$ thermoelectric module. This analysis was carried out in multislice plot and volumetric plot and the mean value was considered as the thermoelectric voltage output $(V)$. The multislice plot displayed 3.56 V whereas volumetric plot displayed 3.69 V. Therefore, thermoelectric voltage $(V)$ of $3.63 \mathrm{~V}$ was considered to perform further analysis.

\section{Conclusions}

Based on present studies following conclusions have been made.

1) $\mathrm{Pb}_{1-\mathrm{x}} \mathrm{Mg}_{\mathrm{x}} \mathrm{Te}_{0.8} \mathrm{Se}_{0.2}$ and $n$-type $\mathrm{PbTe}, \mathrm{Pb}_{1-\mathrm{x}} \mathrm{Mg}_{\mathrm{x}} \mathrm{Te}_{0.8} \mathrm{Se}_{0.2}$ and $\mathrm{CoSb}_{3-\mathrm{x}} \mathrm{Te}_{\mathrm{x}}, \mathrm{Cu}_{12} \mathrm{Sb}_{4} \mathrm{~S}_{13}$ and $\mathrm{CoSb}_{3-\mathrm{x}} \mathrm{Te}_{\mathrm{x}}$ showed higher efficiency, thus, could be used in making efficient thermoelectric generators.

2) $\mathrm{Pb}_{1-\mathrm{x}} \mathrm{Mg}_{\mathrm{x}} \mathrm{Te}_{0.8} \mathrm{Se}_{0.2}$ and $\mathrm{CaMn}_{0.98} \mathrm{Nb}_{0.02} \mathrm{O}_{3}$ showed efficiency below $5 \%$, thus, could not be used in making an efficient thermoelectric generator.

3) Lead telluride based thermoelectric modules could be used in isolated areas due to the toxicity of lead.

4) Tetrahedrite based thermoelectric module could be used in non-isolated areas due to its non-toxic properties and higher cost-efficiency.

5) $\mathrm{Pb}_{1-\mathrm{x}} \mathrm{Mg}_{\mathrm{x}} \mathrm{Te}_{0.8} \mathrm{Se}_{0.2}$ and $\mathrm{CoSb}_{3-\mathrm{x}} \mathrm{Te}_{\mathrm{x}}$ thermoelectric module showed maximum thermoelectric power output.

\section{References}

[1] Kan Chen Synthesis and Thermoelectric Properties of Cu-Sb-S Compounds. Queen Mary University of London, 2016, p. 13-142.

[2] Tomes P., Robert R., Trottmann M., Bocher L., Aguirre M. H., Bitschi A., Hejtmanek J., Weidenkaff A. Synthesis and characterization of new ceramic thermoelectrics implemented in a thermoelectric oxide module. Journal of Electronic Materials, Vol. 39, 2010, p. 1696-1703.

[3] Fu Tiezheng, Yue Xianqiang, Wu Haijun, Fu Chenguang, Zhu Tiejun, Liu Xiaohua, Hu Lipeng, Ying Pingjun, He Jiaqing, Zhao Xinbing Enhanced thermoelectric performance of PbTe bulk materials with figure of merit $z T>2$ by multi-functional alloying. Journal of Materiomics, Vol. 2, Issue 2, 2016, p. 141-149. 
[4] Liang Tao, Su Xianli, Yan Yonggao, Zheng Gang, She Xiaoyu, You Yonghui, Uher Ctirad, Kanatzidis Mercouri G., Tang Xinfeng Panoscopic approach for high-performance Te-doped skutterudite. NPG Asia Materials, Vol. 9, 2017, p. 2-9.

[5] Lan Song, Yang Zhijia, Stobart Richard, Chen Rui Prediction of the fuel economy potential for a skutterudite thermoelectric generator in light-duty vehicle applications. Applied Energy, Vol. 231, 2018, p. 68-79.

[6] Mane Pradyumn, Atheaya Deepali Performance analysis of thermoelectric generator by using lead telluride, perovskites, skutterudites and tetrahedrites. WEENTECH proceedings in Energy, Vol. 5, Issue 2, 2019, p. 66-78. 